
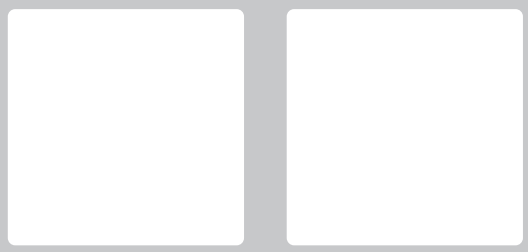

\title{
PROPOSTA DE UM DICIONÁRIO DE TERMOS DE EMOÇÃO EM TEXTOS FINANCEIROS
}

\section{Proposal for a Dictionary of Emotional Terms in Financial Texts}

\section{Sonia Raifur Kos}

Universidade Estadual do Centro Oeste (UNICENTRO). email:soniarkos@yahoo.com.br

\section{Jorge Eduardo Scarpin}

Offut School of Bussiness (Concordia College).

email:jscarpin@gmail.com

\section{José Simão De Paula Pinto}

Universidade Federal do Paraná (UFPR). email:simao@ufpr.br

\section{RESUMO}

O Objetivo é propor um Dicionário de Termos de Emoção em Textos Financeiros, composto de palavras que detectam a presença ou não das emoções - Alegria, Medo, Raiva, Repugnância, Surpresa e Tristeza - em textos financeiros. Partiu-se do Dicionário de Sentimentos Positivos e Negativos em Finanças, disponível na língua inglesa, o qual foi traduzido para o português. Na sequência, especialistas em Finanças e Psicologia alocaram os termos oriundos da tradução para seis emoções básicas estudadas. Por fim, o software Tropes foi ajustado para incorporar as expressões do dicionário, possibilitando a detecção de emoção em textos financeiros de forma eletrônica. O presente estudo constrói um Dicionário de Termos de Emoção em Textos Financeiros, composto por 301 expressões de Alegria; 155 de Medo; 136 de Raiva; 109 de Repugnância; 70 de Surpresa; e 233 de Tristeza, o qual pode ser utilizado para detectar e quantificar as emoções presentes nos relatórios financeiros.

Palavras-Chave: Emoções; Dicionário de Termos; Ambiente financeiro; Análise de Textos

\section{ABSTRACT}

The objective is to propose a Dictionary of Emotions in Finance, composed of words that detect the presence or not of emotions - Joy, Fear, Anger, Disgust, Surprise and Sadness - in financial texts. It started from the Dictionary of Positive and Negative Feelings in Finance, available in English, which was translated into Portuguese. Following this, experts in Finance and Psychology have allocated the terms from the translation to six basic emotions studied. Finally, the Tropes software was adjusted to incorporate the dictionary expressions, allowing the detection of emotion in financial texts in electronic way. The present study creates a Dictionary of Emotion Terms in Financial Text, composed of 301 expressions of Joy; 155 of Fear; 136 of Anger; 109 of Disgust; 70 of Surprise; and 233 of Sadness, which can be used to detect and quantify emotions present in financial reporting.

Key-words: Emotions; Dictionary of Terms; Financial environment; Text Analysis 


\section{INTRODUÇÃO}

A emoção há muito tempo é utilizada como um recurso para as empresas atingirem seus objetivos (FINEMAN, 2001). McPhail (2004) sugere que o desenvolvimento de habilidade emocional é crucial para o engajamento com o mundo, pois, segundo ele, a emoção é o centro de toda tomada de decisão racional. $\mathrm{O}$ autor afirma que a partir de uma perspectiva crítica, a emoção pode ser vista como um facilitador fundamental nos nossos processos de tomada de decisão, e de uma perspectiva ainda mais radical, é possível conceituar a razão como um tipo particular de emoção.

Os textos financeiros têm sido vistos ao longo do tempo como algo puramente racional, ou seja, desprovido de aspectos emocionais. Porém, a Psicologia defende que não se pode conceber um ambiente ou um indivíduo onde a emoção não esteja presente. Nesse sentido, pesquisas têm sido feitas (SOUZA BRITO; CESARINO, 2016; CHAUDURI, 2006; LARÁN; ROSSI, 2006; ASHFORTH; KREINER, 2002;including normalizing. We define normalizing as institutionalized processes by which extraordinary situations are rendered seemingly ordinary. Four means of normalizing are discussed: (1 FINEMAN, 2001; KANAANE, 1999) no intuito de compreender o comportamento humano e identificar quais elementos o influenciam. A emoção tem sido frequentemente citada como elemento relevante nesse processo. Se empresas são formadas por indivíduos [que reportam (informações financeiras) e recebem (investidores) informações] que são, antes de qualquer coisa, humanos, pode-se esperar que informações contábeis (aquelas divulgadas na forma narrativa) possuam carga emocional e, consequentemente, possam influenciar o mercado.

Estados emocionais, melhores ou piores, afetam o processamento cognitivo como planejamento, atenção, memória, criatividade, resolução de problemas, tomada de decisão, memória de trabalho, controle comportamental e processamento da linguagem (MITCHELL; PHILLIPS, 2007). Na vida cotidiana, a linguagem é frequentemente utilizada como uma ferramenta poderosa para provocar emoções. Literatura e poesia são exemplos de como a linguagem pode nos fazer sentir emoções profundas. No entanto, estudos sobre os efeitos emocionais induzidos pela linguagem ainda são raros. Apenas recentemente demonstrou-se que os processos emocionais induzidos pela linguagem são, em muitos aspectos, semelhantes aos desencadeados por estímulos não-linguísticos, tais como imagens, filmes, ou faces (COSTA et al., 2010; SCHACHT; SOMMER, 2009). Pesquisas na área da Psicologia mostram que as palavras utilizadas para explicar como as pessoas se expressam, muitas vezes têm mais poder informativo do que o que as pessoas estão expressando (PENNEBAKER; MEHL; NIEDERHOFFER, 2003).

Lima (2006) relata que no Brasil existem poucas referências que podem auxiliar na reflexão do papel da emoção no discurso de modo geral, sendo, portanto, um campo fértil para a verificação da emoção, haja vista que ela é muito presente na cultura brasileira. Especialmente no ambiente contábil financeiro, a escassez de referências é percebida tanto na quantidade de estudos relacionados à emoção quanto em instrumentos que poderiam ser utilizados para desenvolver pesquisas nessa área. Não há na língua portuguesa nenhum dicionário de termos de emoção específico para análise de textos financeiros.

A detecção da emoção em textos pode ser realizada por meio de uma abordagem baseada em aprendizagem de máquina ou por abordagem léxica. A primeira aplica algoritmos baseados em características linguísticas, enquanto a segunda depende de fontes lexicais, tais como léxicos, lista de palavras ou ontologias (CANALES; MARTÍNEZ-BARCO, 2014). Analisando as fontes disponíveis, percebe-se que os léxicos sobre emoções, de forma geral, são menos extensos (SENTIWORDNET (ESULI; SEBASTIANI, 2006)) que os léxicos de sentimentos. Já o WORDNET-AFFECT (STRAPPARAVA; VALITUTTI, 2004), contém tanto léxicos de sentimentos como de emoções. Um léxico de sentimentos positivos e negativos em finanças foi proposto por Loughran e McDonald (2011), considerado adequado para analisar textos financeiros, no entanto este não aborda emoções específicas, limitando-se a polaridade dos sentimentos.

É oportuno esclarecer que os termos Emoção e Sentimentos são coisas distintas, apesar de serem, não raramente, utilizados como sinônimos. Stets 
(2006), explica que essa confusão se deve ao fato de ambos referirem-se às experiências resultantes das influências biológicas, cognitivas e sociais. No entanto, segundo Davidson, Scherer, e Goldsmith (2003), as emoções são episódios rápidos de alterações cerebrais e comportamentais, provocadas por algum estímulo externo, enquanto os sentimentos apresentam reações mais longas e estáveis, provenientes desta emoção e retrata como o indivíduo se sente.

As emoções, diferente dos sentimentos (positivo ou negativo), descrevem tipos muito mais complexos de estados afetivos associados com fenômenos tais como tristeza, medo ou alegria. A natureza mais complexa da emoção implica na distinção analítica entre Análise de sentimentos e Detecção da emoção, especialmente no que se refere aos léxicos que caracterizam cada uma (MUNEZERO et al., 2014).

A emoção é inerente ao ser humano e está presente em todas suas ações. A mesma influencia de forma significativa as ações e as decisões dos indivíduos. A Psicologia tem dedicado esforços para entender as várias nuances da emoção na vida das pessoas, todavia percebe-se carência de pesquisas sobre esse tema na área contábil, especialmente no que se refere a detecção de emoção em textos financeiros, alguns dos quais tem sido usado de forma expressiva pelas empresas para complementar e justificar as informações presentes nos demonstrativos contábeis. Assim, visando preencher essa lacuna, o presente estudo toma como base o dicionário proposto por Loughran e McDonald (2011), composto por expressões que representam sentimentos positivos e negativos em finanças, visa identificar quais expressões representam as emoções Alegria, Medo, Raiva, Repugnância, Surpresa e Tristeza em textos financeiros?

Nesse sentido, o objetivo principal do presente estudo é propor um Dicionário de Termos de Emoção em Textos Financeiros, composto de palavras que permitam detectar a presença ou não das emoções - Alegria, Medo, Raiva, Repugnância, Surpresa e Tristeza - em textos financeiros de empresas brasileiras.

Considerando que a emoção desempenha um papel significativo nas estruturas sociais e é parte inevitável da tomada de decisão, então certamente merece mais atenção do que tem sido dada a ela na literatura contábil e financeira. Nesse sentido, a contribuição dessa pesquisa reside no desenvolvi- mento de uma ferramenta - Dicionário de Termos de Emoção em Textos Financeiros - que permitirá melhorar o acervo de estudos envolvendo emoção na área financeira, especialmente na detecção da mesma nos relatórios divulgados pelas empresas aos usuários externos.

\section{REFERENCIAL TEÓRICO}

As pesquisas em Psicologia indicam que existem várias teorias sobre como representar emoções (COWIE; CORNELIUS, 2003)it is necessary to have methods of describing emotion. Finding appropriate methods is not straightforward, and there are difficulties associated with the most familiar. The word emotion itself is problematic: a narrow sense is often seen as \"correct।", but it excludes what may be key areas in relation to speech - including states where emotion is present but not full-blown, and related states (e.g., arousal, attitude, no entanto duas são as mais importantes e mais frequentemente utilizadas: a) categorias emocionais e b) dimensões emocionais (FRANCISCO; GERVÁS, 2013)a corpus of example texts previously annotated by human evaluators is mined for an initial assignment of emotional features to words. This results in a list of emotional words (LEW. A abordagem de categoria emocional, é focada em modelos emocionais baseados em classes emocionais distintas, assumindo que existem categorias discretas de emoção. O modelo de emoções de Ekman et al. (1969), no qual seis emoções distintas são categorizadas, representa essa abordagem. Já a abordagem de dimensão emocional considera o afeto na forma dimensional, em que cada emoção ocupa uma locação nesse espaço, sendo dividida em dimensão de valência e dimensão de excitação (CANALES; MARTÍNEZ-BARCO, 2014). Calvo e Kim (2013) mencionam que a abordagem categórica é mais comumente utilizada nos estudos, devido a sua simplicidade e familiaridade.

O dicionário WORDNET-AFFECT, proposto por Strappavara e Mihalcea (2008), apresenta palavras relacionadas às emoções analisadas no estudo de Ekman et al., (1969). Esse dicionário, na versão em língua portuguesa, foi utilizado por Martinazzo (2010); nele constam 279 termos que 
remetem Alegria; 71 palavras catalogadas como Repugnância, 103 expressões que representam Medo, 167 vocábulos que indicam Raiva, 39 palavras vinculadas à Surpresa e 183 expressões de Tristeza. Entretanto, esse dicionário é formado por expressões gerais, não vinculadas diretamente ao mercado financeiro, sendo, portanto, inadequado para detecção de emoção em textos financeiros.

Outro dicionário disponível na literatura relacionado a expressões que remetem a sentimentos positivos e negativos é o proposto por Loughran e McDonald (2011). Os autores tomaram como base o Dicionário Harvard General Inquirer - GI, desenvolvido por Stone, Danphy, Smith e Ogilvie (1966). O GI contém expressões de sentimento positivo e negativo aplicado a aspectos gerais. Loughran e McDonald (2011) testaram o GI e identificaram que o mesmo não era eficiente para análise de sentimentos em textos financeiros, pois algumas expressões que constavam como negativas no GI teriam contexto positivo em finanças. Loughran e McDonald (2011) identificaram que três quartos das palavras negativas encontradas em relatórios financeiros $(10 \mathrm{~K}$, por exemplo) de acordo com o GI, não eram negativas em um contexto financeiro.

Em virtude disso, Loughran e McDonald (2011), doravante chamado de L\&M (2011), propuseram um novo dicionário adaptado para o ambiente econômico-financeiro. Esse dicionário apresenta 2345 expressões relacionadas a sentimentos negativos e 355 termos com contexto positivo (considerado o radical e as derivações). Esse dicionário foi utilizado como base para a construção do léxico proposto neste estudo, chamado de Dicionário de Termos de Emoção em Textos Financeiros. Estudos mostram que os resultados são significativamente mais fortes para medidas que utilizam o dicionário personalizado (HENRY, 2008; LOUGHRAN; MCDONALD, 2011).

As técnicas de detecção de emoção em textos são divididas em abordagem baseada em léxicos e abordagem de aprendizagem de máquinas. A primeira depende de fontes lexicais, tais como léxicos, conjuntos de palavras ou ontologias, enquanto a segunda aplica algoritmos baseados em características linguísticas (CANALES; MARTÍNEZ-BARCO, 2014).
Segundo Canales e Martinez-Barco (2014), na abordagem baseada em léxicos são encontradas três modalidades de detecção de emoção: a) abordagem baseada em palavras-chave; b) abordagem baseada em ontologia; e c) abordagem estatística. Esse estudo utiliza a primeira abordagem.

A abordagem baseada em palavras-chave utiliza um conjunto predeterminado de termos (dicionário) para classificar os textos dentro de categorias emocionais. Uma forma bastante utilizada é por meio da frequência das palavras constantes no dicionário. Strapparava e Mihalcea (2008) implementaram um algoritmo que checou a presença de palavras afetivas (Dicionário WORDNET-AFFECT) nos títulos de notícias e computou uma pontuação que refletia a frequência dessas palavras no texto (CANALES; MARTINEZ-BARCO, 2014).

A abordagem baseada em ontologia é uma forma de detecção de emoção em textos por meio de conhecimento de senso comum. O EmotiNet, que modela as situações como uma cadeia de ações, e seus efeitos emocionais correspondentes, usando uma representação ontológica, é uma ferramenta utilizada para detecção de emoção nessa abordagem (CANALES; MARTINEZ-BARCO, 2014).

A abordagem estatística analisa a relação entre um conjunto de documentos e os termos nele mencionados para produzir um grupo de padrões significativos relacionados aos documentos e aos termos (DEERWESTER et al., 1990). A Análise Semântica Latente (LSA) tem sido usada na maioria dos trabalhos que utilizam essa abordagem (CANALES; MARTINEZ-BARCO, 2014).

O dicionário proposto neste estudo, o qual visa identificar qual a emoção presente nos relatórios financeiros, utiliza a abordagem baseada em léxicos, seguindo a mesma linha dos estudos desenvolvidos por Strapparava e Mihalcea (2008), Gill, French, Gergle e Oberlander (2008), Balahur et al. (2011), Sykora, Jackson, O’Brien e Elayan (2013) e Wang e Zheng (2013). 


\section{METODOLOGIA E DESENVOLVIMENTO}

\subsection{Construção do Dicionário de Termos de Emoção em Textos Financeiros}

\section{Parte 1 Tradução do Dicionário Original - L\&M (2011)}

O primeiro passo no processo construção do dicionário proposto neste estudo é a tradução do dicionário L\&M (2011), visto que o mesmo só está disponível na língua inglesa.

O dicionário proposto por Loughran e McDonald - L\&M (2011) está disponível no site http://www3. nd.edu/ mcdonald/Word_Lists.html, e foi elaborado levando em consideração o significado das palavras no ambiente financeiro. Apresenta um conjunto de expressões divididas em 7 grupos: 355 palavras positivas, 2345 palavras negativas (entre as quais estão incluídas 905 palavras de litígio, 299 palavras de incerteza, 184 palavras de constrangimento, 57 palavras de supérfluos e 69 palavras de interesse). Como o referido dicionário não está disponível em português, foi necessário traduzi-lo para na sequência alocar as expressões para uma das emoções básicas estudadas para torná-lo apto na análise de textos em português.

O dicionário L\&M é composto pela palavra raiz e suas derivações, por exemplo, o termo positivo "beneficial" aparece 7 vezes no dicionário, pois além da raiz constam também "beneficially", "benefit", "benefited", "benefiting", "benefitted" e "benefitting". Antes de iniciar o processo de tradução, portanto, foram mantidas apenas as expressões principais. Desse modo, dos 355 termos positivos do Dicionário L\&M, restaram 167 palavras, e dos 2345 termos negativos restaram 949 expressões. Na sequência, iniciou-se o processo de tradução para o português.

Para realizar a tradução, cada termo constante no dicionário original foi analisado semanticamente, pois é preciso entender o significado do termo em português. Assim, muitas palavras tiveram várias traduções e todas as que apresentavam o mesmo significado do termo original e estavam relacionadas ao ambiente financeiro foram selecionadas. Por exemplo, o termo "gain" foi traduzido como ganho, benefício, aumento, lucro, proveito, vantagem e prosperidade.
Para algumas expressões em inglês não há na língua portuguesa uma única palavra que a represente, gerando assim expressões compostas, como no caso de "clawback", traduzido neste trabalho como: "recuperação de desembolsos/benefícios monetários concedidos". O dicionário Investwords.com traduz essa expressão como um "benefício financeiro ou de outra natureza que é concedido, mas resgatado mais tarde, devido a circunstâncias peculiares". Um exemplo comum é quando investimentos em particular são comprados, rendem benefícios fiscais ao comprador, e, se tais investimentos forem vendidos antes de sua maturação, exige-se que os benefícios fiscais sejam reembolsados [ao governo].

A tradução e análise de todas as palavras do dicionário original foi inicialmente realizada pelos autores deste estudo e, em seguida, validado por três profissionais: o primeiro, um especialista na tradução de textos na área de negócios, o segundo, um especialista da língua inglesa (professor de letras português-inglês) e o terceiro, um docente na área de finanças com domínio da língua inglesa, os quais fizeram as devidas correções exigidas pela língua.

Para validar a tradução, os profissionais envolvidos fizeram uso dos seguintes dicionários: 1 . WordNet; 2. Business Dictionary; 3. Law.com; 4. Merriam Webster; 5. The Free Dictionary; 6. Investor Words; 7. Dicionário Caldas Aulete; 8. Dicionário Priberam da Língua Portuguesa (DPLP); 9. Glossário Jurídico do Supremo Tribunal Federal; 10. Wiktionary; e 11. Diccionário-internacional.com. Após as correções dos especialistas da língua inglesa foram otidas 398 expressões positivas e 1371 negativas.

\section{Parte 2 Alocação dos Termos traduzidos de L\&M para o Dicionário de Termos de Emoção em Textos Financeiros}

A segunda parte do processo de construção do dicionário proposto neste estudo se deu por meio de validação por especialistas em Finanças e em Psicologia. Cada especialista foi convidado a classificar um conjunto de palavras de acordo com a emoção que a mesma poderia gerar em um leitor de texto financeiro. Caso o especialista entendesse que a palavra não 
era capaz de produzir nenhuma emoção, essa opção poderia ser indicada.

A tradução do dicionário L\&M (2011) resultou em 1769 expressões (simples e compostas), representando um volume considerável de termos, tornando inviável que todo conjunto fosse exposto de uma só vez para o especialista convidado. Assim, 20 subconjuntos foram formados, permitindo que o profissional da área classificasse aproximadamente 90 expressões. Cada subconjunto foi classificado por, pelo menos, três especialistas de Finanças e três psicólogos.

Primeiramente cada subconjunto de expressões foi encaminhado para três profissionais de Finanças. Cada expressão teria que ser direcionada para determinada emoção por, pelo menos, dois dos três especialistas, para ser adicionada na lista de expressões definidas. Todas as expressões indefinidas, ou seja, aquelas sobre as quais não houve consenso entre os profissionais de Finanças (cada especialista direcionou para uma emoção diferente) foram classificadas de acordo com a opinião dos profissionais de Psicologia.

O conteúdo emocional textual analisado neste estudo está relacionado com as seis emoções básicas apresentadas por Ekman et al., (1969): Alegria, Repugnância, Medo, Raiva, Surpresa e Tristeza. Por meio de um experimento realizado em vários países, os autores mostravam fotos com diversas expressões faciais para os participantes que precisavam identificar as respostas emocionais apresentadas. O estudo indicou que as seis emoções básicas acima mencionadas foram facilmente interpretadas nas diversas regiões onde o experimento foi realizado. Buechel et al. (2016) afirmam que muitos estudos empregam essa categorização.

\section{Alocação dos Termos de Emoção por Profissionais de Finanças}

Como já mencionado, a primeira fase de validação do dicionário de termos de emoção em Finanças ocorreu por meio da participação de 60 especialistas na área. Foram consultados profissionais da área acadêmica (professores de universidades públicas e privadas e pesquisadores da área) e empresarial (diretores e consultores de empresas). Os primeiros foram escolhidos pelo conhecimento teórico/científico, enquanto os segundos apresentavam a vivência prática das empresas, bem como participavam tanto da elaboração quanto do uso das informações presentes nos relatórios financeiros divulgados pelas empresas. O perfil detalhado dos especialistas convidados é apresentado na Figura 1.

Ao observar o perfil dos especialistas em Finanças, percebe-se que: a) quanto à idade, a maior parte dos respondentes tem mais de 40 anos, representando $68 \%$ do grupo, indicando que os representantes dessa área são pessoas com longa experiência; b) quanto ao sexo, o grupo é essencialmente masculino, o que é característico da área financeira; c) quanto à área de formação, foram consultados especialmente profissionais de administração e contabilidade, no entanto alguns profissionais de outras áreas que atuam no ambiente financeiro também foram inquiridos, como Engenharia de Produção, Sistema de Informação e Economia; d) quanto à titulação, o grupo é representado por mestres e doutores em sua maioria; e) quanto à empresa que atuam, grande parte é vinculada à Instituição Pública de Ensino Superior, no entanto o grupo também é representado por IES Privada, Empresa Privada e Empresa Pública; e f) quanto à função que ocupa, a grande maioria é formada por professores, seguidos de diretores de empresas.

Vê-se que a maioria dos especialistas do grupo são professores de universidades públicas e privadas. Esse público está constantemente envolvido em pesquisa científica e sua contribuição para esse estudo é certamente relevante. Por outro lado, foram ouvidos diretores de empresas que são as pessoas responsáveis pela divulgação das informações ao público externo, sendo, portanto, especialistas importantes dentro do grupo.

Como mencionado acima, o conjunto de palavras resultantes da tradução do dicionário L\&M (2011) foi dividido em 20 subconjuntos, os quais foram enviados de forma aleatória para os especialistas de Finanças, de modo que cada subconjunto fosse avaliado por três profissionais diferentes. Os profissionais foram convidados a classificar as expressões, orientados da seguinte forma: "Considerando textos na área financeira, identifique qual emoção (Alegria, Medo, Raiva, Repugnância, Surpresa ou Tristeza) é despertada por cada termo listado. Se nenhuma emoção estiver relacionada com a expressão, escolha 


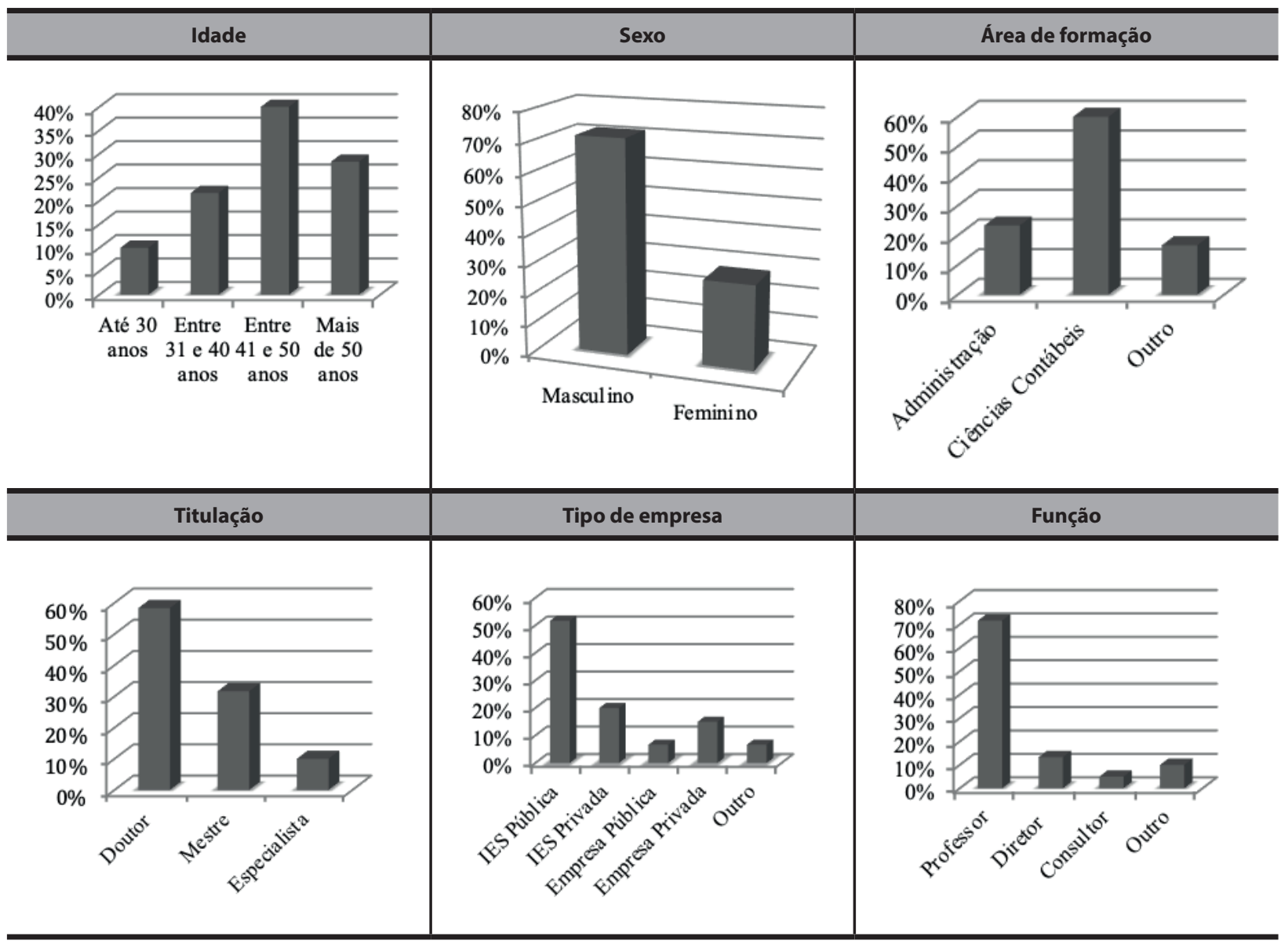

Figura 1 Infográfico - Perfil dos Especialistas de Finanças

Fonte: Elaborado pelos autores

a coluna 'nenhuma emoção'". Em seguida, cada termo que recebeu a mesma classificação por, pelo menos, dois dos três especialistas foi direcionado para a respectiva emoção. O mesmo procedeu-se quando um termo foi considerado com "nenhuma emoção".

Essa etapa da pesquisa proporcionou a construção da primeira parte do dicionário, formado exclusivamente por profissionais da área de negócios. Essa fase culminou na alocação de 257 termos para Alegria, 77 expressões para Medo, 83 para Raiva, 85 foram consideradas como Repugnância, 47 para Surpresa e 161 termos foram alocados para Tristeza. Nessa fase, 534 termos foram considerados com nenhuma emoção.

Recorda-se que a tradução do trabalho de Loughran e McDonald (2011) resultou em 1769 termos. Nesta etapa, 1244 expressões foram classificadas, no entanto não houve consenso entre os especialistas de Finanças sobre os outros 525 termos, visto que cada profissional deu aos mesmos uma classificação distinta.

\section{Alocação dos Termos de Emoção por Profissionais de Psicologia}

A segunda fase de validação do Dicionário de Termos de Emoção em Textos Financeiros ocorreu por meio da participação de 60 profissionais de Psicologia (psicólogos clínicos, psicólogos organizacionais, professores de instituições públicas e privadas e pesquisadores) compreendendo, dessa forma, diversas habilidades na área de Psicologia. Estes especialistas foram responsáveis pela classificação dos termos indefinidos pelo primeiro grupo. Mais informações sobre o perfil desses profissionais estão demonstradas na Figura 2.

Observa-se que os profissionais desse grupo têm, na maioria (60\%), até 40 anos de idade, são do 


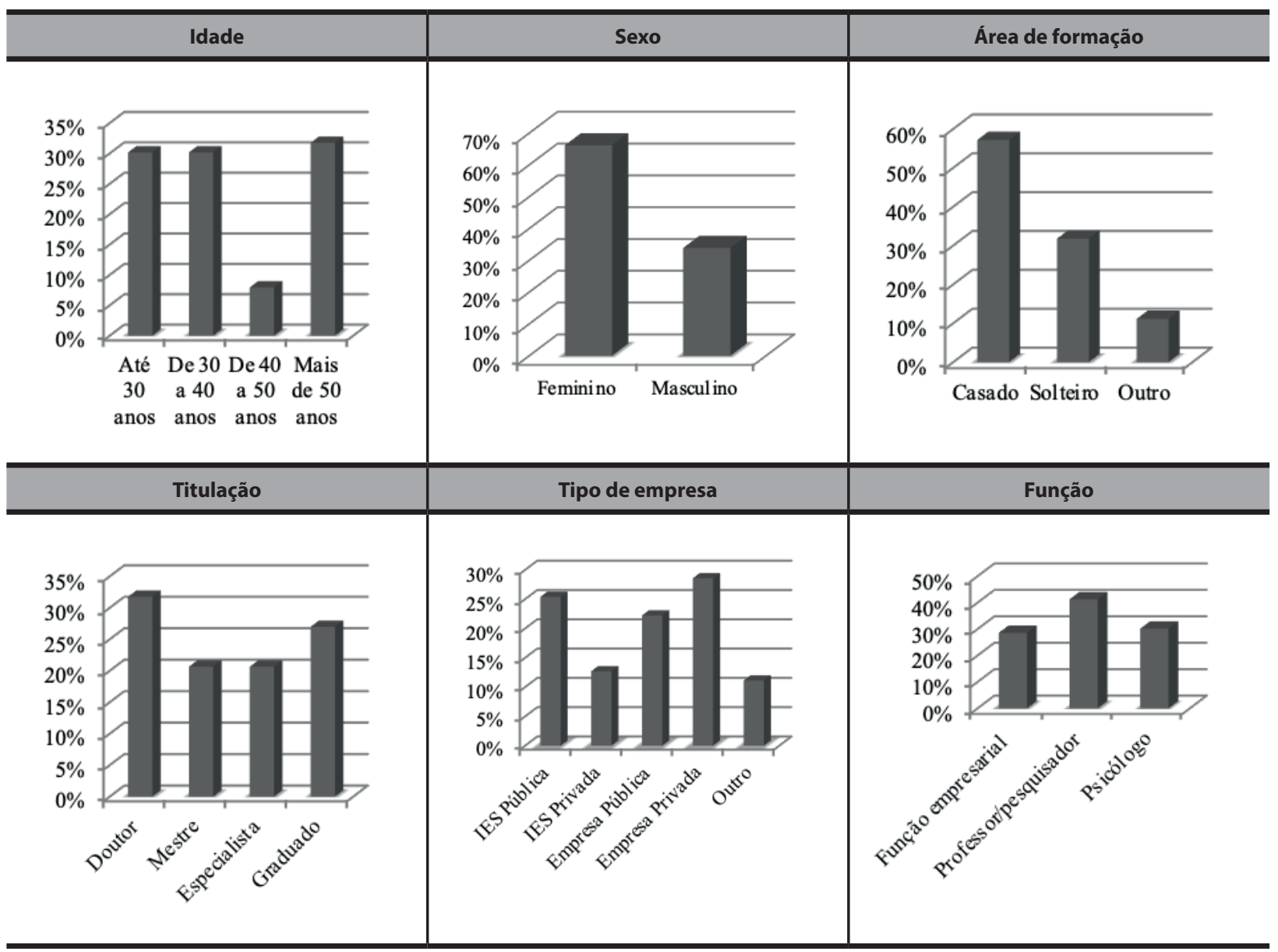

Figura 2 Infográfico - Perfil dos especialistas em Psicologia

Fonte: Elaborado pelos autores

sexo feminino e casados. Ao contrário dos profissionais de negócios, os especialistas são mais jovens e é mais comum a atuação das mulheres. Quanto à titulação, vê-se que houve participação equilibrada, estando presente graduados, especialistas, mestres e doutores. Era intuito do estudo mesclar a opinião de profissionais atuantes na área clínica com opinião de docentes, sendo graduação e especialização as titulações daqueles que atuam estritamente como psicólogos, e mestrado e doutorado dos que atuam com professores universitários.

Quanto ao tipo da organização em que o profissional atua, destaca-se o vínculo com empresas privadas, representadas por consultórios de Psicologia e instituições nas quais atuam principalmente como gestores de recursos humanos. Percebe-se também que a maior parte dos docentes tem vínculo com uma Instituição Pública de Ensino Superior.
Seguindo a mesma metodologia dos profissionais de Finanças, os profissionais de Psicologia classificaram os termos indefinidos. Essa fase culminou na alocação de 44 termos para Alegria, 78 expressões para Medo, 53 para Raiva, 24 foram consideradas como Repugnância, 23 para Surpresa e 72 termos foram alocados para Tristeza. Nessa fase, 231 termos foram considerados como não representativo de nenhuma emoção.

A versão final do Dicionário de Termos de Emoção em Textos Financeiros, construído com base no dicionário L\&M (2011), cuja tradução foi validada por especialistas da língua inglesa e a alocação dos termos para as emoções foi avalizada por especialista em Finanças e Psicologia, é composta por: 301 expressões de Alegria; 155 de Medo; 136 de Raiva; 109 de Repugnância; 70 de Surpresa; e 233 de Tristeza. 


\subsubsection{Emoção Alegria}

A emoção Alegria é representada nos textos pela presença de expressões que induzem à sensação positiva, tais como felicidade e satisfação: Por exemplo: Abono, Abundância, Confiança, Conquista, Determinação, Digno, Força, Ganhar, Honestidade, Meritório, Lucro, Rendimento, Vencer, entre outras. Percebe-se que as palavras presentes nesse grupo podem desencadear um sentimento de alegria nos diversos usuários dos relatórios corporativos. Os leitores de textos financeiros com ênfase na Alegria tendem a sentir segurança e confiança nas organizações. As 301 expressões relacionadas à Alegria estão disponíveis na Tabela 1.

Tabela 1 Expressões de Alegria em Textos Financeiros

\begin{tabular}{|c|c|}
\hline$\square$ Abastança & $\square$ Boa reputação \\
\hline$\square$ Abono & $\square$ Bom \\
\hline$\square$ Abrandar & $\square$ Bondoso \\
\hline$\square$ Abrilhantar & $\square$ Bonito \\
\hline$\square$ Abundância & $\square$ Brilhante \\
\hline$\square$ Acalmar & $\square$ Brio \\
\hline$\square$ Acessivel & $\square$ Calmo \\
\hline$\square$ Aclamado & $\square$ Capaz \\
\hline$\square$ Acolhedor & $\square$ Caridade \\
\hline$\square$ Adiantamento & $\square$ Caridoso \\
\hline$\square$ Admirar & $\square$ Categórico \\
\hline$\square$ Afável & $\square$ Cativante \\
\hline$\square$ Afirmativo & $\square$ Certo \\
\hline$\square$ Afortunado & $\square$ Clareza \\
\hline$\square$ Agradável & $\square$ Colaborar \\
\hline$\square$ Ajuda & $\square$ Compensação \\
\hline$\square$ Alcançar & $\square$ Competência \\
\hline$\square$ Alegre & $\square$ Vontade \\
\hline$\square$ Alertar & $\square$ Completar \\
\hline$\square$ Aliança & $\square$ Compreensível \\
\hline$\square$ Alívio & $\square$ Conceder herança \\
\hline$\square$ Amável & $\square$ Conciliação \\
\hline$\square$ Aperfeiçoar & $\square$ Concluir \\
\hline$\square$ Apoiar & $\square$ Concordar \\
\hline$\square$ Aprazível & $\square$ Condecoração \\
\hline$\square$ Apreciável & $\square$ Confiança \\
\hline$\square$ Aprimorar & $\square$ Congratulação \\
\hline$\square$ Apto & $\square$ Conquista \\
\hline$\square$ Aquisição & $\square$ Consagrado \\
\hline$\square$ Aquisição & $\square$ Constância \\
\hline$\square$ Assegurar & $\square$ Construtivo \\
\hline$\square$ Atingir (objetivo) & $\square$ Consulta \\
\hline$\square$ Atitude & $\square$ Contente \\
\hline$\square$ Atraente & $\square$ Convicção \\
\hline$\square$ Auxílio & $\square$ Convincente \\
\hline$\square$ Avanço & $\square$ Cooperação \\
\hline$\square$ Baratear & $\square$ Cordial \\
\hline$\square$ Belo & $\square$ Delicioso \\
\hline$\square$ Bem & $\square$ Descoberta \\
\hline$\square$ Benéfico & $\square$ Descobrir \\
\hline$\square$ Benemérito & $\square$ Desejável \\
\hline$\square$ Benfeitoria & $\square$ Desempenho superior \\
\hline$\square$ Benigno & $\square$ Desfrutar \\
\hline
\end{tabular}

\begin{tabular}{|c|c|c|}
\hline & Despreocupação & $\square$ Homenagem \\
\hline$\square$ & Destaque & $\square$ Honestidade \\
\hline$\square$ & Determinação & $\square$ Honorável \\
\hline$\square$ & Devidamente & $\square$ Honra \\
\hline$\square$ & Digno & $\square$ Ideal \\
\hline $\bar{\square}$ & Diligente & $\square$ Ilustre \\
\hline$\square$ & Dinamismo & $\square$ Imbatível \\
\hline$\square$ & Disciplinar & $\square$ Imperioso \\
\hline$\square$ & Distinção & $\square$ Importância \\
\hline$\square$ & Diversão & $\square$ Incentivado \\
\hline $\bar{\square}$ & Divulgar & $\square$ Incontestável \\
\hline$\square$ & Duradouro & $\square$ Incrivel \\
\hline$\square$ & Efetivo & $\square$ Indenização \\
\hline $\bar{\square}$ & Efetuar & $\square$ Influência \\
\hline $\bar{\square}$ & Eficaz & $\square$ Informativo \\
\hline$\square$ & Eficiência & $\square$ Inovação \\
\hline$\square$ & Elevar & $\square$ Instrutivo \\
\hline$\square$ & Elogio & $\square$ Integridade \\
\hline$\square$ & Emoção & $\square$ Inteireza \\
\hline$\square$ & Emocionar & $\square$ Intenso \\
\hline$\square$ & Empolgado & $\square$ Invencível \\
\hline$\square$ & Encantado & $\square$ Justificável \\
\hline $\bar{\square}$ & Encorajar & $\square$ Líder \\
\hline$\square$ & Energético & $\square$ Lisonjeiro \\
\hline$\square$ & Energia & $\square$ Louvável \\
\hline $\bar{\square}$ & Engrandecer & $\square$ Lucro \\
\hline$\square$ & Entreter & $\square$ Mais alto \\
\hline$\square$ & Entusiasmo & $\square$ Melhor \\
\hline$\square$ & Escalar & $\square$ Merecedor \\
\hline $\bar{\square}$ & Esclarece & $\square$ Meritório \\
\hline$\square$ & Esforço & $\square$ Momento de alta \\
\hline$\square$ & Espetacular & $\square$ Muito \\
\hline$\square$ & Estabilidade & $\square$ Notável \\
\hline$\square$ & Estável & $\square$ Notório \\
\hline$\square$ & Estímulo & $\square$ Obtenção \\
\hline$\square$ & Evolução & $\square$ Ocasião propícia \\
\hline$\square$ & Excelência & $\square$ Oportunidade \\
\hline$\square$ & Excepcional & $\square$ Otimista \\
\hline$\square$ & Excitação & $\square$ Ótimo \\
\hline$\square$ & Executar & $\square$ Ousadia \\
\hline$\square$ & Exxito & $\square$ Ovacionado \\
\hline $\bar{\square}$ & Êxtase & $\square$ Parceria \\
\hline$\square$ & Extraordinário & $\square$ Perdoar \\
\hline$\square$ & Fácil & $\square$ Perfeição \\
\hline$\square$ & Fantástico & $\square$ Permissão \\
\hline$\square$ & Fartura & $\square$ Perpétuo \\
\hline$\square$ & Favorável & $\square$ Perseverança \\
\hline$\square$ & Favorito & $\square$ Persistir \\
\hline$\square$ & Feliz & $\square$ Perspicaz \\
\hline$\square$ & Fenomenal & $\square$ Plano \\
\hline$\square$ & Fidedigno & $\square$ Plenitude \\
\hline$\square$ & Fiel/fidelidade & $\square$ Posicionar \\
\hline $\bar{\square}$ & Finalizar & $\square$ Positivo \\
\hline $\bar{\square}$ & Firme & $\square$ Possibilitar \\
\hline$\square$ & Firmeza de propósito & $\square$ Postura \\
\hline$\square$ & Folga & $\square$ Prazer \\
\hline$\square$ & Força & $\square$ Preciso \\
\hline$\square$ & Formidável & $\square$ Predileto \\
\hline$\square$ & Formoso & $\square$ Predisposto \\
\hline$\square$ & Ganhar & $\square$ Prêmio \\
\hline$\square$ & Garantia & $\square$ Prestígio \\
\hline$\square$ & Genial & $\square$ Pretensão \\
\hline$\square$ & Gentil & $\square$ Prevenção \\
\hline$\square$ & Gracioso & $\square$ Proativo \\
\hline$\square$ & Grande & $\square$ Processar \\
\hline 믐 & Gratificação & $\square$ Proeza \\
\hline$\square$ & Hábil s & $\square$ Professar (fé) \\
\hline
\end{tabular}




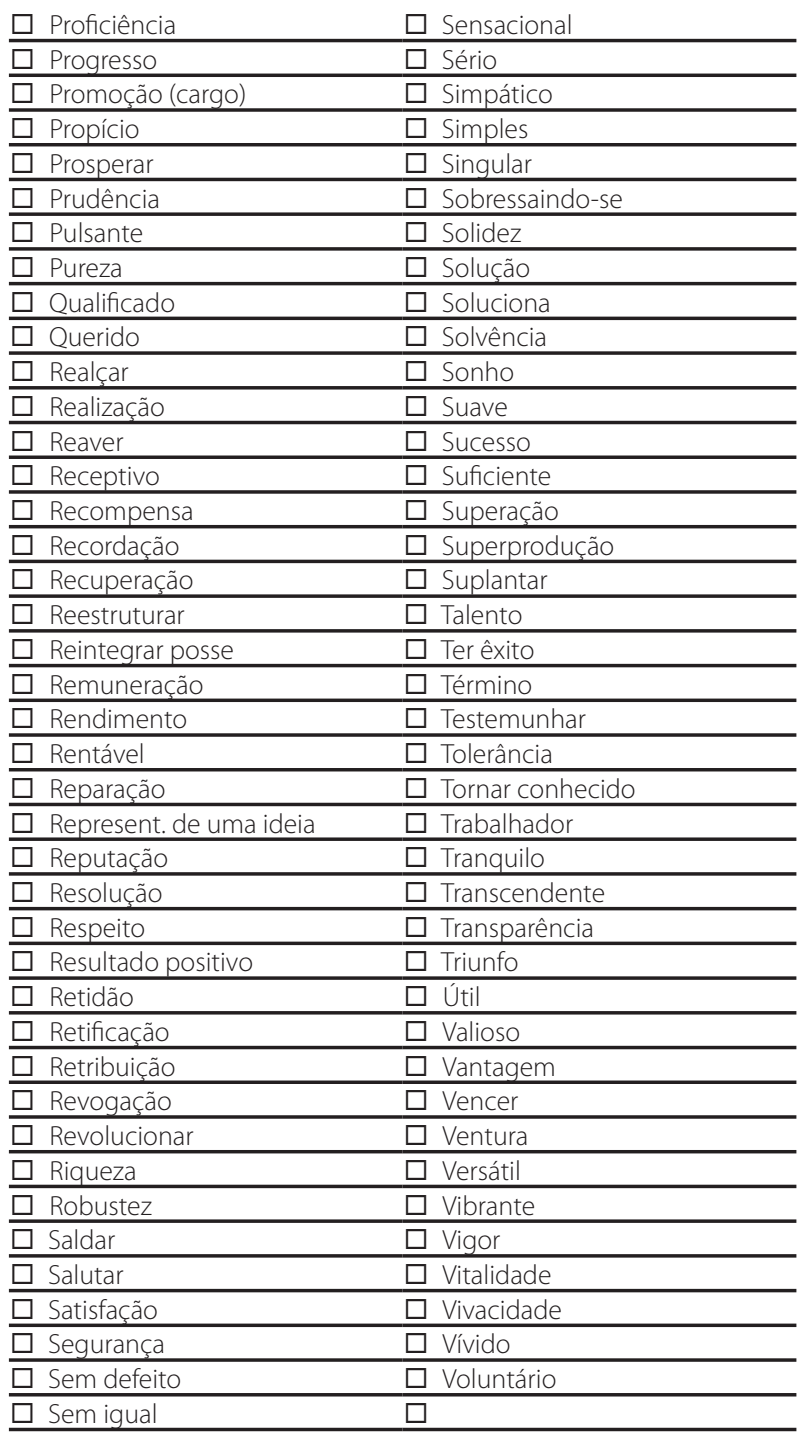

Fonte: Dados da pesquisa

\section{Emoção Medo}

Um texto que indica que o autor sente medo ao produzi-lo ou que induz a sensação de medo em quem os lê, possui expressões como: Aflição, Coerção, Colapso, Crise, Dívida, Incerteza, Insolvência, Litígio, Oculto, Oneroso, Perigo, Prisão, Sinistro, entre outras. As palavras desse conjunto induzem o leitor do texto a sensações negativas. Ao ler expressões dessa natureza, o usuário pode não se sentir seguro com a organização e tender a buscar novos negócios. As 155 expressões relacionadas a Medo estão disponíveis na Tabela 2.
Tabela 2 Expressões de Medo em Textos Financeiros

\begin{tabular}{|c|c|}
\hline$\frac{\square \text { Abater }}{\square \text { Acabar }}$ & $\frac{\square \text { Gana }}{\square \text { Hinoteca }}$ \\
\hline $\begin{array}{l}\text { A Acabar } \\
\square \text { Advogar }\end{array}$ & $\begin{array}{l}\text { प Hipoteca } \\
\square \text { Hostil }\end{array}$ \\
\hline $\begin{array}{l}\square \text { Advogar } \\
\square \text { Afetar }\end{array}$ & $\square$ Ilegal \\
\hline Aflição & $\square$ Imperativo \\
\hline$\square$ Agravar & Q Imprevisível \\
\hline$\square$ Ameaça & प Improbidade \\
\hline$\square$ Arriscar & Q Imprudência \\
\hline$\square$ Assalto & 口 Inadvertido \\
\hline$\square$ Ataque & $\begin{array}{l}\square \text { Inapropriado } \\
\end{array}$ \\
\hline$\square$ Atrasar & $\square$ Incerteza \\
\hline$\overline{\square \text { Cautela }}$ & प Incitar \\
\hline$\square$ Cercar & प Inclinado (a fazer) \\
\hline$\overline{\square \text { Coerção }}$ & 口 Inconfiável \\
\hline$\square$ Colapso & $\square$ Indevido \\
\hline$\square$ Colisão & $\square$ Infração \\
\hline$\square$ Colocar em risco & $\square$ Ingerência \\
\hline [ Combinação inadequada & $\square$ Inquérito \\
\hline Condenar & Inquietação \\
\hline$\square$ Confinar & Q Insalubridade \\
\hline ] Conspiração & प Insolvência \\
\hline$\square$ Construir algo & $\square$ Instabilidade \\
\hline demasiado grande & $\bar{I}$ Insuficiência \\
\hline$\square$ Contenção & $\square$ Interrogatório \\
\hline$\square$ Crise & $\square$ Intimação \\
\hline$\square$ Delicado & प Intimidar \\
\hline$\square$ Derrota & $\square$ Inversão \\
\hline$\square$ Derrubar & 口 Inviável \\
\hline$\square$ Desabrigar & $\square$ Lesionar \\
\hline$\square$ Desalojar & $\square$ Levar aos tribunais \\
\hline$\square$ Descapacitar-se & $\square$ Litígio \\
\hline$\square$ Descapitalizado & $\square$ Má fama \\
\hline$\square$ Desconhecer & $\square$ Malignidade \\
\hline$\square$ Desconsiderar & $\square$ Medo \\
\hline$\overline{D \text { Desorganizado }}$ & प Não estabilizado \\
\hline D Desregulado & $\begin{array}{l}\square \text { Não saudável } \\
\end{array}$ \\
\hline$\square$ Destituir & $\square$ Não segurado \\
\hline$\square$ Detenção & $\square$ Notificação \\
\hline$\square$ Devastar & $\square$ Obscurecer \\
\hline D Difícil/Dificuldade & $\square$ Obstáculo \\
\hline$\square$ Dilema & $\square$ Oculto \\
\hline$\square$ Dirigir mal & $\square$ Ofuscar \\
\hline$\square$ Disputa & $\square$ Oneroso \\
\hline$\square$ Distendido & $\square$ Ônus \\
\hline$\square$ Dívida & $\square$ Ordem Judicial \\
\hline$\square$ Dor & $\square$ Ordenar (dar ordem) \\
\hline D Dúbio & $\begin{array}{l}\text { Pânico } \\
\end{array}$ \\
\hline$\square$ Eliminar & $\square$ Paralisação \\
\hline Em detrimento de & $\square$ Pavor \\
\hline$\square$ Embaraço & $\begin{array}{l}\text { Perigo } \\
\end{array}$ \\
\hline Empobrecer & $\square$ Perturbação \\
\hline$\overline{\square \text { Encarcerar }}$ & प Precipitado \\
\hline$\square$ Encrenca & $\square$ Predatório \\
\hline$\square$ Enfrentar & $\square$ Preocupação \\
\hline$\square$ Entravar & $\square$ Presidiário \\
\hline$\square$ Equívoco & $\square$ Pressionar \\
\hline$\square$ Escuro & $\begin{array}{l}\square \text { Prisão } \\
\end{array}$ \\
\hline Estagnação & $\square$ Processos Inconclusivos \\
\hline$\square$ Explosão & $\square$ Proibição \\
\hline D Extremo & $\square$ Punição \\
\hline$\square$ Fechar & $\begin{array}{l}\square \text { Questionável } \\
\end{array}$ \\
\hline$\square$ Flagrante & $\square$ Receio \\
\hline 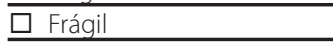 & $\square$ Recessão \\
\hline$\overline{\text { Fratura }}$ & $\square$ Recuo \\
\hline$\square$ Fuga & $\square$ Redução \\
\hline
\end{tabular}




\begin{tabular}{ll}
$\square$ Relutância & $\square$ Severo \\
\hline$\square$ Repreensão & $\square$ Sinistro \\
\hline$\square$ Reprimir & $\square$ Sofrer \\
\hline$\square$ Resistência & $\square$ Sombrio \\
\hline$\square$ Ressonância & $\square$ Substituir \\
\hline$\square$ Retração & $\square$ Superestimar \\
\hline$\square$ Revidar & $\square$ Suscetível \\
\hline$\square$ Risco & $\square$ Temor \\
\hline$\square$ Romper & $\square$ Tensão \\
\hline$\square$ Seguro insuficiente & $\square$ Terror \\
\hline$\square$ Sem documento & $\square$ Tropeço \\
\hline$\square$ Sem garantia & $\square$ Turbulência \\
\hline$\square$ Sem seguro & $\square$ Urgência
\end{tabular}

Fonte: Dados da pesquisa

\section{Emoção Raiva}

Segundo o dicionário proposto, expressões como: Afronta, Aviltamento, Boicote, Calúnia, Coação, Depredar, Difamar, Distorção, Injustiça, Intriga, Morosidade, Propina, Roubo, Trapaça, entre outras, estão relacionadas à emoção raiva. A presença de termos com essa semântica induz a rejeição de organizações com esse tipo de expressão textual. As 136 expressões relacionadas à raiva estão disponíveis na Tabela 3.

Tabela 3 Expressões de Raiva em Textos Financeiros

\begin{tabular}{ll}
$\square$ Afronta & $\square$ Desavença \\
\hline$\square$ Aborrecer & $\square$ Desdém \\
\hline$\square$ Acusação & $\square$ Desentendimento \\
\hline$\square$ Administração danosa & $\square$ Desequilíbrio \\
\hline$\square$ Antiético & $\square$ Desfavorável \\
\hline$\square$ Apontado erroneamente & $\square$ Desfigurar \\
\hline$\square$ Atormentar & $\square$ Desistência \\
\hline$\square$ Atrapalhar & $\square$ Destruir \\
\hline$\square$ Avaliação incorreta do preço & $\square$ Detrair \\
\hline$\square$ Avaliar mal & $\square$ Difamar \\
\hline$\square$ Aviltamento & $\square$ Discordar \\
\hline$\square$ Boicote & $\square$ Dissimulação \\
\hline$\square$ Caiu & $\square$ Dissuadir \\
\hline$\square$ Calote & $\square$ Distorção \\
\hline$\square$ Calúnia & $\square$ Empecilho \\
\hline$\square$ Carga & $\square$ Empregar indevidamente \\
\hline$\square$ Censura & $\square$ Encurralar \\
\hline$\square$ Coação & $\square$ Enganar \\
\hline$\square$ Combater & $\square$ Exploração \\
\hline$\square$ Complicar & $\square$ Fazer pouco caso \\
\hline$\square$ Confrontar & $\square$ Fazer vista grossa \\
\hline$\square$ Contradizer & $\square$ Fixação errônea de preço \\
\hline$\square$ Controvérsia & $\square$ Furioso \\
\hline$\square$ Crime & $\square$ Gargalo \\
\hline$\square$ Delito & $\square$ Grosseiro \\
\hline$\square$ Delongar & $\square$ Ilegível \\
\hline$\square$ Denegrir & $\square$ Implicar \\
\hline$\square$ Vítima & $\square$ Importunar \\
\hline$\square$ Depredar & $\square$ Imposto \\
\hline$\square$ Desacato & $\square$ Inaceitável \\
\hline$\square$ Desaceleração & $\square$ Inadimplência \\
\hline$\square$ Desatenção & $\square$ Inadmissível \\
\hline &
\end{tabular}

\begin{tabular}{ll}
$\square$ Incoerência & $\square$ Não amigável \\
\hline$\square$ Inconveniência & $\square$ Não executado \\
\hline$\square$ Incorreto & $\square$ Não pago \\
\hline$\square$ Induzir ao erro & $\square$ Não planejado \\
\hline$\square$ Ineficácia & $\square$ Obstrução \\
\hline$\square$ Infligido & $\square$ Obtenção de vantagem \\
\hline$\square$ Informação errada & $\square$ Ódio \\
\hline$\square$ Informar mal & $\square$ Omissão \\
\hline$\square$ Infundado & $\square$ Operação tartaruga \\
\hline$\square$ Injustiça & $\square$ Oportunista \\
\hline$\square$ Inoportuno & $\square$ Opulência \\
\hline$\square$ Insistência & $\square$ Pago em excesso \\
\hline$\square$ Insubordinação & $\square$ Pane \\
\hline$\square$ Intriga & $\square$ Penalidade \\
\hline$\square$ Invasão & $\square$ Pendência \\
\hline$\square$ Inverdade & $\square$ Perjúrio \\
\hline$\square$ Irresponsável & $\square$ Perseguir \\
\hline$\square$ Irritação & $\square$ Preço abusivo \\
\hline$\square$ Juízo equivocado & $\square$ Preconceito \\
\hline$\square$ Julgamento invalido & $\square$ Propina \\
\hline$\square$ Julgar mal & $\square$ Reembolso \\
\hline$\square$ Letargia & $\square$ Relatar erroneamente \\
\hline$\square$ Limitação & $\square$ Remarcação de preços \\
\hline$\square$ Má aplicação & $\square$ Represália \\
\hline$\square$ Má classificação & $\square$ Retaliação \\
\hline$\square$ Mal aplicado & $\square$ Ríspido \\
\hline$\square$ Mal dirigido & $\square$ Roubo \\
\hline$\square$ Mal pago & $\square$ Sabotagem \\
\hline$\square$ Mal rotulado & $\square$ Servidão forçada \\
\hline$\square$ Maldade & $\square$ Tentativa de agressão \\
\hline$\square$ Manipular & $\square$ Traição \\
\hline$\square$ Mau & $\square$ Trama ou acordo secreto \\
\hline$\square$ Minimizar o valor & $\square$ Transgredir \\
\hline$\square$ Moralmente ofensivo & $\square$ Trapaça \\
\hline$\square$ Morosidade & $\square$ Uso incorreto \\
\hline$\square$ Multa & $\square$ Vagaroso \\
\hline$\square$ (n) &
\end{tabular}

Fonte: Dados da pesquisa

\section{Emoção Repugnância}

Nesse conjunto estão presentes palavras como: Adulterar, Anticoncorrencial, Assimetria, Clandestino, Desonesto, Despeito, Escândalo, Falsidade, Fútil, Fraude, Insulto, Malícia, Quadrilha, Repulsa, Ultraje, Vingança, entre outras. Termos com essa conotação estão relacionados com aspectos negativos. Os usuários das informações financeiras expostos a estes tipos expressões tendem a se afastar dessa organização uma vez que a sensação passada no texto é de dificuldade. As demais expressões que estão relacionadas à repugnância estão disponíveis na Tabela 4 .

Tabela 4 Expressões de Repugnância em Textos Financeiros

\begin{tabular}{ll}
$\square$ Admoestação & $\square$ Alongar \\
\hline$\square$ Abusar & $\square$ Anticoncorrencial \\
\hline$\square$ Adulterar & $\square$ Antieconômico \\
\hline$\square$ Afirmar erroneamente & $\square$ Antiquado \\
\hline$\square$ Agiotagem & $\square$ Aperto
\end{tabular}




\begin{tabular}{|c|c|}
\hline$\square$ Apodrecido & $\square$ Lavagem de dinheiro \\
\hline$\square$ Aporrinhar & $\square$ Lesar \\
\hline$\square$ Assimetria & $\square$ Má fé \\
\hline$\square$ Ato Condenável & $\square$ Maleficência \\
\hline$\square$ Atroz & $\square$ Malefício \\
\hline$\square$ Avaria & $\square$ Malícia \\
\hline$\square$ Beligerante & $\square$ Maquiar resultados, balanços \\
\hline$\square$ Burlar & $\square$ Medíocre \\
\hline$\square$ Castigado & $\square$ Menosprezar \\
\hline$\square$ Clandestino & $\square$ Mentira \\
\hline$\square$ Conduta ilegal & $\square$ Mesquinhez \\
\hline$\square$ Contaminar & $\square$ Minar \\
\hline$\square$ Contravenção & $\square$ Molestar \\
\hline$\square$ Depravado & $\square$ Não confiável \\
\hline$\overline{\square \text { Depreciativo }}$ & $\square$ Não moral \\
\hline$\square$ Desagradável & $\square$ Negligência \\
\hline$\square$ Desatualizado & $\square$ Nocivo \\
\hline$\square$ Descrédito & $\square$ Nojento \\
\hline$\overline{\square \text { Desgraça }}$ & $\square$ Objeção \\
\hline$\square$ Desleal & $\square$ Obsceno \\
\hline$\square$ Desmentido & $\square$ Ofertado em excesso \\
\hline$\square$ Desonesto & $\square$ Paga mal \\
\hline$\square$ Despeito & $\square$ Pervasivo \\
\hline$\square$ Desrespeitar & $\square$ Perverso \\
\hline$\square$ Desvalorizar & $\square$ Peso morto \\
\hline$\square$ Desviar & $\square$ Pichação \\
\hline$\square$ Devasso & $\square$ Prevaricação \\
\hline$\square$ Discórdia & $\square$ Provocar \\
\hline$\square$ Embaçado & $\square$ Quadrilha \\
\hline$\square$ Escândalo & $\square$ Repelir \\
\hline$\square$ Estorvar & $\square$ Repúdio \\
\hline$\square$ Exacerbar & $\square$ Repugnante \\
\hline$\square$ Falsidade & $\square$ Repulsa \\
\hline$\square$ Fingir & $\square$ Ridículo \\
\hline$\square$ Fraude & $\square$ Saquear \\
\hline$\square$ Fútil & $\square$ Sem validade legal \\
\hline$\square$ Ignorante & $\square$ Subfinanciado \\
\hline$\square$ Ilícito & $\square$ Subjugação \\
\hline$\square$ Imoral & $\square$ Suborno \\
\hline$\overline{\square \text { Imperícia }}$ & $\square$ Temperamental \\
\hline$\square$ Inábil & $\square$ Tirar vantagem \\
\hline$\square$ Indecência & $\square$ Tumulto \\
\hline$\square$ Indignidade & $\square$ Ultraje \\
\hline$\square$ Ineficiência & $\square$ Usurpar \\
\hline $\bar{\square}$ Inexatidão & $\square$ Vandalismo \\
\hline$\square$ Infiltrar-se & $\square$ Vingança \\
\hline$\square$ Insulto & $\square$ Violar \\
\hline$\square$ Intencional & $\square$ Violência \\
\hline$\square$ Intrusão & $\square$ Vomitar \\
\hline$\square$ Irregularidade & $\square$ \\
\hline
\end{tabular}

Fonte: Dados da pesquisa

\section{Emoção Surpresa}

As expressões classificadas como surpresa estão relacionadas a algo não esperado. Estão listados nesse grupo termos como: Acaso, Brusco, Desavisado, Egrégio, Ilógico, Inacreditável, Inesperado, Inexorável, Mistério, Novidade, Perplexo, Precoce, Reviravolta, Segredo, Súbito, Volátil, entre outros. As expressões desse conjunto podem tanto representar contextos positivos quanto negativos, como exposto na Tabela 5.

Tabela 5 Expressões de Surpresa em Textos Financeiros

\begin{tabular}{|c|c|}
\hline$\square$ Acaso & $\square$ Insuperável \\
\hline$\square$ Acionar & $\square$ Justificativa parcial \\
\hline$\square$ Agarrar & $\square$ Mistério \\
\hline$\square$ Alegar & $\square$ Modificar radicalmente \\
\hline$\square$ Antecipação & $\square$ Não agendado \\
\hline$\square$ Argumentar & $\square$ Não anunciado \\
\hline$\square$ Atencioso & $\square$ Não contabilizado \\
\hline$\square$ Atrito & $\square$ Não previsto \\
\hline$\square$ Aumentar & $\square$ Não receptivo \\
\hline$\square$ Aviso & $\square$ Não revelado \\
\hline$\square$ Brusco & $\square$ Novidade \\
\hline$\square$ Choque & $\square$ Perplexo \\
\hline$\square$ Citação Judic. & $\square$ Pior (que) \\
\hline$\square$ Classificação Errônea & $\square$ Pleitear \\
\hline$\square$ Confessar & $\square$ Posto no lugar errado \\
\hline$\square$ Contrapor & $\square$ Precoce \\
\hline$\square$ Contratempo & $\square$ Protesto \\
\hline$\square$ Desaguar & $\square$ Readquirir \\
\hline$\square$ Desavisado & $\square$ Reavaliação \\
\hline$\square$ Deslize & $\square$ Recusar \\
\hline$\square$ Desmedido & $\square$ Repentino \\
\hline$\square$ Desnudo & $\square$ Revelação \\
\hline$\square$ Digressão & $\square$ Reverberância \\
\hline$\square$ Disparidade & $\square$ Reversão de pena \\
\hline$\square$ Distração & $\square$ Reviravolta \\
\hline$\square$ Egrégio & $\square$ Revisão \\
\hline$\square$ Façanha & $\square$ Saída ou exclusão de ações \\
\hline$\square$ Hesitação & $\square$ Segredo \\
\hline$\square$ llógico & $\square$ Situação sem saída \\
\hline$\square$ Inacessível & $\square$ Súbito \\
\hline$\square$ Inacreditável & $\square$ Superproduz \\
\hline$\square$ Incontrolável & $\square$ Suspeito \\
\hline$\square$ Inesperado & $\square$ Travessura \\
\hline$\square$ Inexorável & $\square$ Vencido \\
\hline$\square$ Inigualável & $\square$ Volátil \\
\hline
\end{tabular}

Fonte: Dados da pesquisa

\section{Emoção Tristeza}

Nesse grupo estão inclusos os termos que induzem a sensação de tristeza, ou seja, sentimento negativo, tais como: Abandono, Calamidade, Catástrofe, Demissão, Desemprego, Desgaste, Dispendioso, Dissolução, Embargo, Escassez, Estresse, Falência, Frustração, Grave, Inativo, Negativo, Obsoleto, Perda, Prejuízo, Queixa, Transtorno, entre outros. A existência de termos dessa natureza nos relatórios produz sensações negativas aos leitores. As expressões relacionadas à emoção tristeza estão disponíveis na Tabela 6. 
Tabela 6 Expressões de Tristeza em Textos Financeiros

\begin{tabular}{|c|c|c|}
\hline$\square$ Abdicar & $\square$ & Desperdiçar \\
\hline$\square$ Abaixo dos padrões & $\square$ & Desprezo \\
\hline$\square$ Abandonar & $\square$ & Despromover \\
\hline$\square$ Absenteísmo & $\square$ & Desqualificar \\
\hline$\square$ Administrar mal & $\square$ & Desregrado \\
\hline$\square$ Advertência & $\square$ & Desvantagem \\
\hline$\square$ Algo/Alguém cuja & $\square$ & Deturpar \\
\hline falta é sentida & $\bar{\square}$ & Diminuir \\
\hline$\square$ Alterado & $\square$ & Dispendioso \\
\hline$\square$ Anticompetitivo & $\square$ & Dissolução \\
\hline$\square$ Apelar & $\square$ & Distanciamento \\
\hline$\square$ Aprisionar & $\square$ & Doente/doença \\
\hline$\square$ Arruinar & $\square$ & Drástico \\
\hline$\square$ Assolar & $\square$ & Embargo \\
\hline$\square$ Baixa produção & $\square$ & Encerrar \\
\hline$\square$ Baixo desempenho & $\square$ & Encolhimento \\
\hline$\square$ Bancarrota & $\square$ & Entender erroneamente \\
\hline$\square$ Barreira & $\square$ & Entender mal \\
\hline$\square$ Bloqueio & $\square$ & Escassez \\
\hline$\square$ Calamidade & $\square$ & Esquecer \\
\hline$\square$ Caracterização errônea & $\square$ & Estéril \\
\hline$\square$ Carência & $\square$ & Estrago \\
\hline$\square$ Catástrofe & $\square$ & Estresse \\
\hline$\square$ Chateado & $\square$ & Evadir (impostos) \\
\hline$\square$ Comover & $\square$ & Exclusão \\
\hline$\square$ Compreender mal & $\square$ & Exonerar \\
\hline$\square$ Compulsório & $\square$ & Expelir \\
\hline$\square$ Confiscar & $\square$ & Expropriar \\
\hline$\square$ Constrangimento & $\square$ & Extenuado \\
\hline$\square$ Contorcer & $\square$ & Extravagância \\
\hline$\square$ Delinquência & $\square$ & Falecimento \\
\hline$\square$ Demissão & $\square$ & Falência \\
\hline$\square$ Demolir & $\square$ & Falta \\
\hline$\square$ Demorar & $\square$ & Fardo \\
\hline$\square$ Denúncia & $\square$ & Fatalidade \\
\hline$\square$ Desacreditar & $\square$ & Ferir \\
\hline$\square$ Desafortunado & $\square$ & Fraco/fraqueza \\
\hline$\square$ Desanimar & $\square$ & Frustração \\
\hline$\square$ Desaparecido & $\square$ & Funesto \\
\hline$\square$ Desapontar & $\square$ & Gerir mal \\
\hline$\square$ Desastre & $\square$ & Grave \\
\hline$\square$ Desativado & $\square$ & Imperfeição \\
\hline$\square$ Descartar & $\square$ & Impopular \\
\hline$\square$ Desclassificar & $\square$ & Impossibilitar \\
\hline$\square$ Descontentamento & $\square$ & Imprecisão \\
\hline$\square$ Descrença & $\square$ & Improdutivo \\
\hline$\square$ Descuido & $\square$ & Impurezas \\
\hline \multirow{2}{*}{$\begin{array}{l}\text { Desempenho } \\
\text { inferior a esperado }\end{array}$} & $\square$ & Inapto \\
\hline & $\square$ & Inativo \\
\hline$\square$ Desempenho ruim & $\square$ & Incapaz \\
\hline$\square$ Desemprego & $\square$ & Incomodar \\
\hline$\square$ Desencorajar & $\square$ & Incompetência \\
\hline$\square$ Desestabilizar & $\square$ & Incompleto \\
\hline$\square$ Desestímulo & $\square$ & Indecoroso \\
\hline$\square$ Desfalcar & $\square$ & Indeferir \\
\hline$\square$ Desgaste & $\square$ & Indesejável \\
\hline$\square$ Desiludir & $\square$ & Indigente \\
\hline$\square$ Desincentivo & $\square$ & Indisposição \\
\hline$\square$ Desinteresse & $\square$ & Inevitável \\
\hline$\square$ Desinvestir & $\square$ & Inexequível \\
\hline$\square$ Desleixado & $\square$ & Inexplicado \\
\hline$\square$ Deslocado & $\square$ & Infeliz \\
\hline$\square$ Desmerecer & $\square$ & Inferior \\
\hline$\square$ Desocupado & $\square$ & Infortúnio \\
\hline$\square$ Despedir & $\square$ & Injúria \\
\hline
\end{tabular}

\begin{tabular}{|c|c|c|}
\hline & Insatisfação & $\square$ Péssimo \\
\hline$\square$ & Inseguro & $\square$ Pouco inspirado \\
\hline $\bar{\square}$ & Insensitivo & $\square$ Pré julgamento \\
\hline$\square$ & Insensível & $\square$ Preguiça \\
\hline $\bar{\square}$ & Inundação & $\square$ Prejudicial \\
\hline$\square$ & Inútil & $\square$ Prejuízo \\
\hline$\square$ & Involuir & $\square$ Prematuro \\
\hline $\bar{\square}$ & Irrealista & $\square$ Pretexto \\
\hline$\square$ & |rrealizável & $\square$ Problema \\
\hline$\square$ & |rreconciliável & $\square$ Prorrogar \\
\hline $\bar{\square}$ & Irrecuperável & $\square$ Protelar \\
\hline $\bar{\square}$ & Irreparável & $\square$ Queimado \\
\hline $\bar{\square}$ & Irresoluto & $\square$ Queixa \\
\hline$\square$ & Irreversível & $\square$ Rancor \\
\hline $\bar{\square}$ & |rrevogável & $\square$ Rebaixar \\
\hline$\square$ & Julgado a revelia & $\square$ Recair (sobre) \\
\hline$\square$ & Lamento & $\square$ Reclamação \\
\hline$\square$ & Lentidão & $\square$ Reclusão \\
\hline $\bar{\square}$ & Machucar & $\square$ Regredir \\
\hline $\bar{\square}$ & Magoar & $\square$ Rejeição \\
\hline $\bar{\square}$ & Mal remunerado & $\square$ Renegar \\
\hline$\square$ & Mal remunerado & $\square$ Renunciar \\
\hline$\square$ & Malogro & $\square$ Reprovação \\
\hline$\square$ & Maltratar & $\square$ Réu \\
\hline $\bar{\square}$ & Manobrar & $\square$ Ruim \\
\hline$\square$ & Moratória & $\square$ Ruína \\
\hline$\square$ & Moribundo & $\square$ Ruptura \\
\hline $\bar{\square}$ & Morte & $\square$ Sacrifício \\
\hline$\square$ & Não aprovado & $\square$ Seca \\
\hline $\bar{\square}$ & Não completado & $\square$ Sem brilho \\
\hline$\square$ & Não comprovado & $\square$ Sem êxito \\
\hline $\bar{\square}$ & Não cumprimento & $\square$ Sem força \\
\hline$\square$ & Não declarado & $\square$ Sem sucesso \\
\hline$\square$ & Não funcional & $\square$ Sem trabalho ou emprego \\
\hline$\square$ & Não lucrativo & $\square$ Sem valor \\
\hline $\bar{\square}$ & Não qualificado & $\square$ Sobrecarregado \\
\hline $\bar{\square}$ & Não rentável & $\square$ Subavaliar \\
\hline$\square$ & Não resolvido & $\square$ Subcapitalizado \\
\hline$\square$ & Negação & $\square$ Subdeclaração \\
\hline$\square$ & Negativo & $\square$ Subestimar \\
\hline$\square$ & Obrigar & $\square$ Sumir \\
\hline$\square$ & Obsoleto & $\square$ Súplica \\
\hline$\square$ & Ocioso & $\square$ Tardio \\
\hline $\bar{\square}$ & Ofensa & $\square$ Tortuoso \\
\hline $\bar{\square}$ & Oprimir & $\square$ Tragédia \\
\hline$\square$ & Parada de funcionamento & $\square$ Transtorno \\
\hline $\bar{\square}$ & Pedir demissão & $\square$ Traumático \\
\hline$\square$ & Penoso & $\square$ Tremendo \\
\hline$\square$ & Penúria & $\square$ Tributar pesadamente \\
\hline$\square$ & Percalço & $\square$ Triste \\
\hline$\square$ & Perda & $\square$ Vergonha \\
\hline$\square$ & Pesado & $\square$ Vulnerável \\
\hline $\bar{\square}$ & Pesar & $\square$ \\
\hline
\end{tabular}

Fonte: Dados da pesquisa

O Fluxograma seguido para construção do dicionário pode ser visualizado na Figura 3 a seguir:

O objetivo de construir este dicionário é oferecer uma ferramenta para detectar emoções em textos financeiros, no entanto para que algumas conclusões sejam apuradas faz-se necessário analisar vários relatórios e uma verificação manual se torna inviável. 
Dessa forma, após a conclusão da fase de alocação dos termos para as respectivas emoções, buscou-se um software capaz de realizar as análises de forma eletrônica e automática, partindo dos termos pertencentes no dicionário proposto. Dentre os inúmeros softwares que realizam análise de conteúdo, optou-se pelo Tropes, especialmente pelo mesmo permitir a inserção de dicionários personalizados e aceitar termos compostos.

\subsection{Software Tropes}

Tropes é um software livre de análise textual (mineração de textos), disponível nas línguas inglesa, francesa, espanhola, romena e portuguesa. Realiza análise sintática e semântica e apresenta os resultados em forma de gráficos e tabelas. Essa ferramenta tem sido frequentemente utilizada em estudos nacionais (COSTA; MOTA, 2015; FERREIRA, 2007) e internacionais (ALFONSO et al., 2015; SHIENA et al., 2013; FARTOUKH; CHANQUOY; PIOLAT, 2012; GIGNON et al., 2012; PIOLAT et al., 2011; PIOLAT; BANNOUR, 2009).

O Tropes oferece vários tipos de informação sobre um texto: a) análise estilística/retórica: indica se o texto é argumentativo, enunciativo, descritivo ou narrativo; b) identificação de diferentes categorias de palavras: verbos, conectores (conjunções, frases conjuntivas), modalizadores (advérbios), adjetivos qualificativos, pronomes pessoais, substantivos e nomes próprios; c) detecta estruturas discursivas; e d) análises temáticas: campos de referências.

O software analisa documentos no formato de texto: arquivos do Microsoft Word, ANSI (Windows), HTML (páginas web), RTF, ou outro. Textos financeiros publicados no formato PDF precisam ser transformados para o formato Microsoft Word. O texto pode incluir pontuação, letras maiúsculas ou caracteres especiais (tais como parênteses, números, percentagens, etc.), no entanto, somente letras do alfabeto e caracteres de pontuação são usados durante a análise.

O Tropes permite que várias palavras sejam consideradas em conjunto, para tanto é necessária que as mesmas estejam ligadas com underline no dicionário base. Por exemplo, a palavra "desempenho" se analisada sozinha não transmite nenhuma emoção, no entanto "desempenho positivo" ou "desempenho ruim" representa alegria no primeiro caso e tristeza no segundo. Para que sejam reconhecidas dessa forma no texto, faz-se necessário que as mesmas estejam listadas no Dicionário como "desempenho_positivo" ou "desempenho_ruim".

Piolat e Bannour (2009) afirmam que entre as vantagens do software está sua capacidade de desenvolver análise sintática, semântica e estilística e apresentar os resultados em forma de gráfico e tabela. As análises são realizadas numa base estatística, exigindo que os textos estudados tenham comprimento suficiente para que os resultados sejam significativos.

As análises realizadas pelo software são embasadas nos cenários construídos a partir dos dicionários contidos nele. Uma característica fundamental para escolha do Tropes é que ele possibilita ajustar os dicionários originais ou incluir dicionários personalizados de acordo com as necessidades e objetivos da pesquisa. Esse novo dicionário orienta a análise a partir do novo cenário gerado por ele, possibilitando a detecção da informação que se busca. Piolat e Bannour (2009) construíram um dicionário de emoções na língua francesa chamado EMOTAIX (http:// centrepsycle-amu.fr/outils-recherche/) utilizando o Tropes justamente por ele apresentar essa flexibilidade.

\subsubsection{Inserção do Dicionário de Termos de Emoção em Textos Financeiros}

Para inserir o dicionário no software Tropes foram seguidos quatro passos:

13. as palavras representativas de cada emoção foram listadas em uma planilha de Excel, codificadas de acordo com a exigência do software, salvo como "Texto separado por tabulações ( ${ }^{*}$.txt) e por fim a terminação ".txt” foi transformada em ".scn”. A estrutura do dicionário considera as palavras em três níveis: G\#0V - Representa a Emoção (Classe Equivalente); G\#1V - representa as Referências e $0 \# 2 \mathrm{~V}$ - representa as palavras indicativas da Emoção.

14. um primeiro teste foi realizado permitindo perceber que o software não capturou as flexões das palavras. O mesmo relatório foi analisado utilizando o conjunto de palavras sem 
derivações e com derivações, resultando em 341 expressões capturadas no primeiro caso e 631 no segundo caso. Sendo, portanto, necessário incluir as derivações de cada expressão, como, por exemplo, na palavra Admirar foram inseridas as expressões Admiraram, Admirará, Admirarão, Admiração, Admirado, Admirada, Admirou, Admirando, Admirável, Admira, Admiram, Admiramos, Admirava, Admiravam, Admirávamos e Admiradamente. Após a inclusão das derivações, o conjunto de palavras representativas de cada emoção ficou composto por: 2.375 termos de Alegria; 1.636 de Medo; 1.110 de Raiva; 1.219 de Repugnância; 484 de Surpresa; e 2.130 de Tristeza.

15. importação do arquivo codificado para dentro do software, permitindo o processamento e a captura das emoções de acordo com o dicionário proposto.

16. para verificar se o software faz a captura da emoção de acordo com o dicionário proposto, um protocolo de validação foi realizado. Para tanto, as expressões contidas em cada Emoção foram incluídas no Software AtlasTi que identifica a frequência de cada termo listado no dicionário no texto analisado. $\mathrm{O}$ teste demostrou que o Software Tropes detecta as emoções de forma adequada.

\section{CONSIDERAÇÕES FINAIS}

As emoções, por estarem presentes em todas as ações humanas, exercem papel fundamental nas decisões e merecem mais atenção que tem sido dada a ela na área contábil e financeira. Sabe-se ainda que a principal forma de comunicação das empresas com os usuários externos é por meio de relatórios escritos e os mesmos podem conter conteúdo emocional com vistas a influenciar as decisões.

Viu-se ainda que no Brasil, um país onde a emoção é culturalmente presente, há carência de estudos envolvendo emoção e relatórios financeiros. Percebeu-se ainda a falta de instrumentos que pudessem auxiliar na realização de pesquisas sobre esse tema, indicando a existência de uma lacuna a ser preenchida. Dessa forma o objetivo do estudo foi propor um Dicionário de Termos de Emoção em Textos Financeiros, capaz de detectar as emoções presentes em textos da área de negócios.

O estudo tomou como base o Dicionário de Sentimentos Positivos e Negativos em Finanças, proposto por Loughran e McDonald (2011), o qual foi traduzido para o português e os termos resultados da tradução alocados para as seis emoções básicas, identificadas por Ekman et al. (1969): Alegria, Medo, Raiva, Repugnância, Surpresa e Tristeza, por meio da participação de especialistas em Finanças e em Psicologia. Ao final do processo o dicionário ficou composto por 301 expressões de Alegria; 155 de Medo; 136 de Raiva; 109 de Repugnância; 70 de Surpresa; e 233 de Tristeza.

Por fim o dicionário foi inserido em um software de análise de textos chamado Tropes, o qual permite realizar a análise de textos financeiros de forma eletrônica e automática, viabilizando a investigação de um conjunto maior de textos e, consequentemente, possibilitando a obtenção de conclusões mais robustas.

\section{REFERÊNCIAS}

ALFONSO, S., ERIC, D., UNIT, M. O., HOSPITAL, L. T., \& MELANIE, P. Citation : SANTARPIA, A ., DUDOIT , E ., \& PAUL , M . ( 2015 ). The discursive effects of the haiku-based SADUPA poetry technique in palliative care. Journal of Poetry Therapy, v. 28, n. 3, p. 179-194, 2015.

ASHFORTH, B. E., \& KREINER, G. E. Normalizing emotion in organizations: Making the extraordinary seem ordinary. Human Resource Management Review, 12(2), 215-235. https://doi.org/10.1016/ S1053-4822(02)00047-5, 2002.

BALAHUR, A., HERMIDA, J. M., \& MONTOYO, A. Detecting Implicit Expressions of Sentiment in Text Based on Commonsense Knowledge. Proceedings of the 2nd Workshop on Computational Approaches to Subjectivity and Sentiment Analysis WASSA 2011, 53-60, 2011. 
BUSINESS DICTIONARY. Retrieved from http: file:///www.businessdictionary.com, 2017.

CALVO, R. A., \& MAC KIM, S. Emotions in Text: Dimensional and Categorical Models. Computational Intelligence, 29(3), 527-543. https:// doi.org/10.1111/j.1467-8640.2012.00456.x , 2013.

CANALES, L., \& MARTÍNEZ-BARCO, P. Emotion Detection from Text. Processing in the 5th Information Systems Research Working Days. http://doi.org/10.5121/csit.2012.2237, 2014.

\section{CHAUDURI, A. Emotion and Reason in Consumer}

Behavior. (Elsevier Butterworth-Heinemann, Ed.), 2006.

COSTA, E. P., \& MOTA, M. Q. Estudo piloto sobre o discurso de pesquisas científicas em Design da informação: uma abordagem crítico-semântica da coerência da estrutura textual. Revista Brasileira de Design Da Informação, 12(3), 336-356, 2015.

COSTA, V. D., LANG, P. J., SABATINELLI, D., VERSACE, F., \& BRADLEY, M. M. Emotional imagery: Assessing pleasure and arousal in the brain's reward circuitry. Human Brain Mapping, 31(9), 1446-1457. https://doi.org/10.1002/hbm.20948, 2010.

COWIE, R., \& CORNELIUS, R. R. Describing the emotional states that are expressed in speech. Speech Communication, 40(1-2), 5-32. https://doi. org/10.1016/S0167-6393(02)00071-7, 2003.

DAVIDSON, R. J., SCHERER, K. R., \& GOLDSMITH, H. H. (Eds.). Handbook of affective sciences. New York, NY, US: Oxford University Press, 2003.

DEERWESTER, S., DUMAIS, S. T., FURNAS, G. W., LANDAUER, T. K., \& HARSHMAN, R. A. Indexing by latent semantic analysis. Jasis, 41(6), 391-407. https://doi.org/10.1002/(SICI) 10974571(199009)41:6<391::AID-ASI1>3.0.CO;2-9, 1990.
DICCIONÁRIO-INTERNACIONAL.com. Retrieved from http://ww1.diccionario-internacional.com/, 2017.

DICIONÁRIO CALDAS AULETE. Retrieved from http://www.aulete.com.br/, 2017.

DICIONÁRIO PRIBERAM DA LÍNGUA PORTUGUESA (DPLP). Retrieved from https:// dicionario.priberam.org/ , 2017.

EKMAN, P., SORENSON, E. R., \& FRIESEN, W. V. Pan-Cultural Elements in Facial Displays of Emotions. pdf. Science, New Series, 164(3875 (Apr. 4)), 86-88, 1996.

ESULI, A., \& SEBASTIANI, F. SENTIWORDNET: A Publicly Available Lexical Resource for Opinion Mining. Proceedings of the 5th Conference on Language Resources and Evaluation, 417-422. http://doi.org/10.1.1.61.7217, 2006.

FARTOUKH, M., CHANQUOY, L., \& PIOLAT, A. Effects of Emotion on Writing Processes in Children. Writen Comunication, 24(4), 391-411. https://doi. org/10.1177/0741088312458640, 2012.

FERREIRA, A. A. G. As possibilidades de uso de ferramentas da informática : software para análise de dados qualitativos e ISD 1. Calidoscópio, 5(3), 168-176, 2007.

FINEMAN, S. A emoção e o processo de organizar. In Atlas (Ed.), Handbook De Estudos Organizacionais. São Paulo, 2001.

FRANCISCO, V., \& GERVÁS, P. Emotag: An approach to automated markup of emotions in texts. Computational Intelligence, 29(4), 680-721.

https://doi.org/10.1111/j.1467-8640.2012.00438.x, 2013.

GIGNON, M., IDRIS, H., MANAOUIL, C., \& GANRY, O. The waiting room : vector for health education ? the general practitioner' s point of view. BMC Research Notes, 5, 1-6, 2012. 
GILL, A. J., FRENCH, R. M., GERGLE, D., \& OBERLANDER, J. Identifying Emotional Characteristics from Short Blog Texts. 30th Annual Conference of the Cognitive Science Society, 2237-2242, 2008.

GLOSSÁRIO JURÍDICO DOSUPREMOTRIBUNAL FEDERAL. Retrieved from http://www.stf.jus.br/portal/glossario/listarVerbetes.asp, 2017.

INVESTOR WORDS. Retrieved from http://www. investorwords.com//, 2017.

KANAANE, R. (1999). Comportamento humano nas organizaçöes: o homem rumo ao século XXI. (Atlas, Ed.) (2nd ed.). São Paulo, 1999.

LARÁN, J. A., \& ROSSI, C. A. V. Surpresa e a formação da satisfação do consumidor. RAE Eletrônica, 5(1), 2006.

LAW.COM. Retrieved from https://www.law.com/?slreturn=20190809151211, 2017.

LIMA, H. M. R. Na tessitura do processo penal:: a argumentação no tribunal do júri. (Tese de Doutorado) Universidade Federal de Minas Gerais, Belo Horizonte, MG, Brasil, 2006.

LOUGHRAN, T., \& MCDONALD, B. When is a Liability not a Liability? Journal of Finance, 66(1), 35-65. https://doi.org/10.1111/j.15406261.2010.01625.x, 2011.

MARTinAZZO, B. (2010). Um Método De Identificação De Emoções Em Textos Curtos Para O Português Do Brasil. Biblioteca.Pucpr.Br. (Dissertação de Mestrado) Pontifícia Universidade Catolica do Paraná - PUC-PR, Curitiba, PR, Brasil, 2010.

MCPHAIL, K. An emotional response to the state of accounting education: developing accounting students' emotional intelligence. Critical Perspectives on Accounting, 15(4-5), 629-648. https://doi. org/10.1016/S1045-2354(03)00050-9, 2004.
MERRIAM WEBSTER. Retrieved from https://www. merriam-webster.com/, 2017.

MITCHELL, R. L. C., \& PHILLIPS, L. H. The psychological, neurochemical and functional neuroanatomical mediators of the effects of positive and negative mood on executive functions. Neuropsychologia, 45(4), 617-629. https://doi.org/10.1016/j.neuropsychologia.2006.06.030, 2007.

MUNEZERO, M., MONTERO, C. S., SUTINEN, E., \& PAJUNEN, J. Are they different? affect, feeling, emotion, sentiment, and opinion detection in text. IEEE Transactions on Affective Computing, 5(2), 101-111. 10.1109/TAFFC.2014.2317187, 2014.

PENNEBAKER, J. W., MEHL, M. R., \& NIEDERHOFFER, K. G. Psychological aspects of natural language. use: our words, our selves. Annual Review of Psychology, 54, 547-77. https://doi. org/10.1146/annurev.psych.54.101601.145041, 2003.

PIOLAT, A., \& BANNOUR, R. An example of text analysis software (EMOTAIX-Tropes) use: The influence of anxiety on expressive writing. Current Psychology Letters, 25(2), 1-21, 2009.

PIOLAT, A., BOOTH, R. J., CHUNG, C. K., DAVIDS, M., \& PENNEBAKER, J. W. La version française du dictionnaire pour le LIWC: modalités de construction et exemples d' utilisation The French dictionary for LIWC : Modalities of construction and examples of use. Psychologie Française, 56, 145-159. https:// doi.org/10.1016/j.psfr.2011.07.002, 2011.

PUTTEN, J. VANDER, \& NOLEN, A. L. Comparing Results From Constant Comparative and Computer Software Methods : A Reflection About Qualitative Data Analysis. Journal or Ethnographic \& Qualitative Research, 5(2007), 99-112, 2010.

SCHACHT, A., \& SOMMER, W. Emotions in word and face processing: Early and late cortical responses. Brain and Cognition, 69(3), 538-550. https://doi. org/10.1016/j.bandc.2008.11.005, 2009. 
SHIENA, R. DI, OLIVIER, L., CHANG, B., \& PHILIPPOT, P. Why are Depressive Individuals Indecisive ? Different Modes of Rumination Account for Indecision in Non-clinical Depression. Cognitive Therapy and Research, 37(4), 713-724. https://link. springer.com/article/10.1007/s10608-012-9517-92013.

SOUZA BRITO, I. A. G., \& CESARINO, A. M. Análise do Comportamento e o Fenômeno Emocional. Fragmentos de Cultura, 26(2), 187-196, 2016.

STETS, J. E. Emotions and Sentiments. In J. Delamater (Ed.), Handbook of Social Psychology (pp. 309-335). Boston, MA: Springer US. https://link.springer.com/ chapter/10.1007\%2F0-387-36921-X_13, 2006.

STONE, P. J., DANPHY, D. C., SMITH, M. S., \& OGILVIE, D. M. The General Inquirer: A Computer Approach to Content Analysis. (M.I.T. Press, Ed.). Oxford, 1966.

STRAPPARAVA, C., \& VALITUTTI, A. WordNetAffect: an affective extension of WordNet. Proceedings of the 4th International Conference on Language Resources and Evaluation, 1083-1086. http://www. lrec-conf.org/proceedings/lrec2004/pdf/369.pdf, 2004.

SYKORA, M. D., JACKSON, T. W., O’BRIEN, A., \& ELAYAN, S. Emotive ontology: Extracting fine-grained emotions from terse, informal messages. IADIS International Journal on Computer Science and Information Systems, 8(2), 106-118, 2013.

THE FREE DICTIONARY. Retrieved from http:// http://www.thefreedictionary.com//, 2017.

WANG, X., \& ZHENG, Q. Text Emotion Classification Research Based on Improved Latent Semantic Analysis Algorithm. Proceedings of the 2nd International Conference on Computer Science and Electronics Engineering (ICCSEE 2013), (Iccsee), 210-213. https://doi.org/10.2991/iccsee.2013.55, 2013.

WIKTIONARY. Retrieved from https:// https://en.wiktionary.org/, 2017.
WORDNET. Retrieved from http: http://wordnetweb. princeton.edu/perl/webwn, 2017. 